\title{
Prevalence and clinical associations of wheezes and crackles in the general population: the Tromsø study
}

\author{
J. C. Aviles-Solis ${ }^{1 *}$, C. Jácome ${ }^{2}$, A. Davidsen ${ }^{1}$, R. Einarsen', S. Vanbelle ${ }^{3}$, H. Pasterkamp ${ }^{4}$ and H. Melbye ${ }^{1}$
}

\begin{abstract}
Background: Wheezes and crackles are well-known signs of lung diseases, but can also be heard in apparently healthy adults. However, their prevalence in a general population has been sparsely described. The objective of this study was to determine the prevalence of wheezes and crackles in a large general adult population and explore associations with self-reported disease, smoking status and lung function.

Methods: We recorded lung sounds in 4033 individuals 40 years or older and collected information on self-reported disease. Pulse oximetry and spirometry were carried out. We estimated age-standardized prevalence of wheezes and crackles and associations between wheezes and crackles and variables of interest were analyzed with univariable and multivariable logistic regressions.

Results: Twenty-eight percent of individuals had wheezes or crackles. The age-standardized prevalence of wheezes was $18.6 \%$ in women and $15.3 \%$ in men, and of crackles, 10.8 and $9.4 \%$, respectively. Wheezes were mostly found during expiration and crackles during inspiration. Significant predictors of expiratory wheezes in multivariable analyses were age (10 years increase - OR 1.18,95\%Cl 1.09-1.30), female gender (1.45, 1.2-1.8), self-reported asthma $(1.36,1.00-1.83)$, and current smoking (1.70, 1.28-2.23). The most important predictors of inspiratory crackles were age (1.76, 1.57-1.99), current smoking, (1.94, 1.40-2.69), mMRC $\geq 2$ (1.79, 1.18-2.65), $\mathrm{SpO}_{2}(0.88,0.81-0.96)$, and $\mathrm{FEV}_{1}$ Z-score $(0.86,0.77-0.95)$.

Conclusions: Nearly over a quarter of adults present adventitious lung sounds on auscultation. Age was the most important predictor of adventitious sounds, particularly crackles. The adventitious sounds were also associated with self-reported disease, current smoking and measures of lung function. The presence of findings in two or more auscultation sites was associated with a higher risk of decreased lung function than solitary findings.
\end{abstract}

Keywords: Wheezes, Crackles, Auscultation, Population

\section{Background}

Two hundred years after its invention, the relevance of the stethoscope in modern medical practice has become a topic of debate $[1,2]$. There are some obvious advantages of lung auscultation, such as availability, low cost and non-invasiveness. Lung auscultation remains thus an important part of the respiratory examination, mainly in primary care and in resource-constrained settings.

\footnotetext{
* Correspondence: juan.c.solis@uit.no

${ }^{1}$ General Practice Research Unit, Department of Community Medicine, UIT the Arctic University of Norway, Tromsø, Norway

Full list of author information is available at the end of the article
}

Lung auscultation has shown to be useful in diagnosing various respiratory disorders. Adventitious lung sounds (ALS) such as wheezes and crackles are associated with common diseases like asthma [3], chronic obstructive pulmonary disease (COPD) [4, 5], interstitial lung disease [6], bronchiectasis [7], heart failure [8] and pneumonia [9-11]. Positive findings during auscultation influence clinical decisions such as the rate of antibiotic prescriptions [12,13] and referrals to specialist care [14].

Presence of ALS alone, however, only show moderate sensitivities and specificities, limiting their diagnostic utility [15-17]. This modest accuracy is mainly related

(c) The Author(s). 2019 Open Access This article is distributed under the terms of the Creative Commons Attribution 4.0 International License (http://creativecommons.org/licenses/by/4.0/), which permits unrestricted use, distribution, and 
to the fact that both wheezes and crackles can also be present in apparently healthy adults [10, 18-20]. To determine the real usefulness of ALS it is crucial to define first their behavior, presence and characteristics, in apparently healthy people. Most studies to date, however, have investigated how ALS relate to specific diagnostic categories without considering their distribution across the whole spectrum from health to disease. Moreover, the few existent studies investigating ALS in apparently healthy people used small samples [19], failing to be representative of the general population. The prevalence of wheezes and crackles in a general population has never been reported. [21].

With this study, we aimed to estimate the prevalence of wheezes and crackles in a large general adult population. We also explored to which degree ALS are associated with self-reported disease, smoking status and clinical measures of lung function.

\section{Methods}

\section{Design and participants}

The Tromsø Study is an epidemiological survey that started in 1976 with the main goal to determine the reasons for the high cardiovascular mortality in the municipality of Tromsø, Norway. The study has been periodically repeated with the last survey (7th) taking place in 2015-16.Details of the Tromsø Study can be consulted elsewhere [22, 23].

In this cross-sectional study, our sample consisted of randomly selected participants attending the second visit of the seventh survey of the Tromsø study (Tromsø 7), between May 2015 and October 2016. All Tromsø residents 40 years and older $(n=32,591)$ received a postal invitation to participate in the first visit of Troms $\varnothing 7$. A random sample was selected for the second visit including $20 \%$ of those aged $40-59$ years and $60 \%$ of those aged 60-84 years, and those attending the first visit were invited. In addition, individuals who had participated in previous surveys of the study were invited to obtain repeated measurements. The mean time between the visits was of 52 days $( \pm 32)$. All study participants provided written consent. The Regional Committee for Medical and Health Research Ethics in North Norway approved the study.

\section{Questionnaires and examinations}

In the first visit, the participants filled a questionnaire that included questions on medical conditions such as arterial hypertension, heart failure, atrial fibrillation, COPD, asthma, among others. For each condition, the participants were asked to specify if it was a current diagnosis, if they had that diagnosis at some point in the past or if they never had that diagnosis. They also responded questions about smoking habits. The full questionnaires employed at the Troms $\varnothing$ Study can be consulted in English elsewhere [22].

At the second visit, the participants answered the modified Medical Research Council questionnaire (mMRC) on dyspnea [24]. Dyspnea was further characterized using the question: "How is your breathing today compared to normal?". To better characterize the respiratory status, participants were also asked if they had respiratory infection in the previous week ("Have you had symptoms of common cold, bronchitis or other airway infection the last 7 days?").

Spirometry was performed using SensorMedics Vmax 20c Encore (VIASYS Healthcare Respiratory Technologies, Yorba Linda, CA, USA). Calibration was done daily. We followed the standards of the American Thoracic Society (ATS)/ European Respiratory Society (ERS) [25]. Tests with FEV1 $<0.31$ and with expiration lasting for less than $3 \mathrm{~s}$ were regarded invalid. We did not perform post-bronchodilator measurements. We used the Global Lung Function Initiative (GLI 2012) as a reference [26]. We registered arterial oxygen saturation $\left(\mathrm{SpO}_{2}\right)$ with a pulse oximeter Onyx II model 9550 (Nonin Medical, Inc., Plymouth, MN, USA) after resting $15 \mathrm{~min}$. The highest value after three measurements was registered. We accepted only $\mathrm{SpO}_{2} \geq 80 \%$ due to uncertain validity of lower values $(n=1)$. At the end of this second visit we recorded lung sounds.

\section{Recording of the lung sounds}

We used a microphone MKE 2-EW with a wireless system EW 112-P G3-G (Sennheiser electronic GmbH, Wedemark, Germany), placed in the tube of a Littmann Classic II stethoscope ( $3 \mathrm{M}$, Maplewood MN, USA) at $10 \mathrm{~cm}$ from the headpiece. The signal went to an external sound card (Scarlett 2i2, Focusrite Audio Engineering Ltd., High Wycombe UK) which connected to a computer's audio input. The computer used custom developed software to label the sounds (participant ID, recording site) and allowed us to start the recording with a wireless control (R700, Logitech Europe S.A., Lausanne Switzerland).

We recorded in a quiet room with the participants sitting and the thorax exposed. They were asked to breathe deeper than normal with an open mouth. We started the recordings on inspiration and recorded for $15 \mathrm{~s}$. We performed the same procedure subsequently at six different locations (Fig. 1). The quality of the recordings was monitored using a wireless headset (SDR 160, Sennheiser electronic GmbH, Wedemark, Germany). If the health professional deemed the quality to be unsatisfactory, a second attempt was performed.

We obtained audio files in ".wav" format at a sample rate of $44,100 \mathrm{~Hz}$ and 16-bit depth in a single (monophonic) channel. We did not implement audio filters or other digital pre or post-processing techniques. 


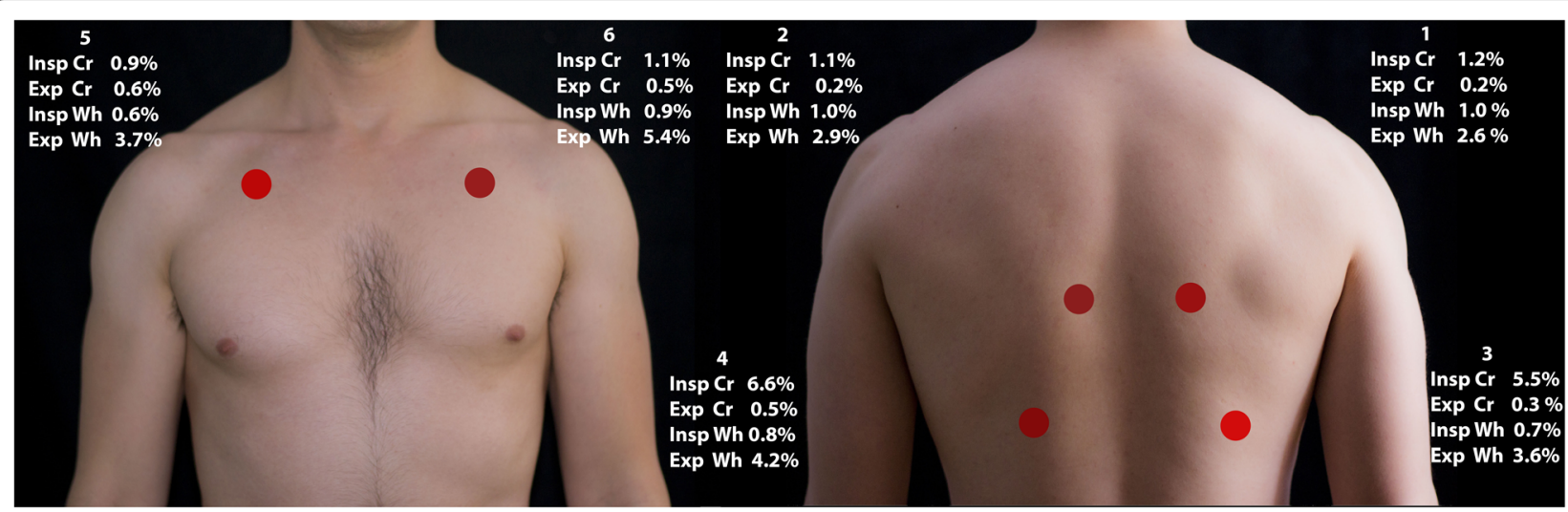

Fig. 1 Recording sites and prevalence of findings. ( 1 and 2) Between the spine and the medial border of the scapula at the level of T4-T5; ( 3 and 4) at the middle point between the spine and the mid-axillary line at the level of T9-T10; (5 and 6) at the intersection of the mid-clavicular line and second intercostal space. $\mathrm{Cr}=$ crackles, Wh $=$ wheezes, Insp = inspiratory, Exp= expiratory

\section{Classification of the recordings}

The classification process consisted of three steps.

At the first step, two observers independently listened to all the recordings with a headset and simultaneously viewed the sound spectrograms using Adobe Audition 5.0 (Adobe Systems, San Jose, CA, USA). J.C.A. was observer 1 and either R.E., A.D. or C.J. were observer 2. They evaluated if the recording contained wheezes (including rhonchi), crackles or other ALS and whether these were heard in inspiration or expiration. They entered their findings in an electronic form (Access, Microsoft Corporation, Redmond WA, USA) and registered if artefactual noise made the classification difficult. The observers could listen to the recordings with freedom to stop or repeat parts or the whole recording if necessary. They were blinded to any information about the participant. Agreement and kappa statistics were calculated accounting for the clustered structure of the data using the R package "magree". [27].

At the second step, all disagreements were evaluated with the two initial observers and a third experienced observer (H.M.). The three observers listened to the sounds and solved disagreements through consensus. If consensus was difficult to reach at this point, the sounds were submitted for classification at the third step.

At the third step, all recordings classified as containing ALS were re-classified by two pairs of observers consisting of one junior (J.C.A. and C.J.) and senior (H.P. and H.M.) lung sound researcher each. These observers had the possibility to mark the findings as "certain", "possible" or "absent". A finding was changed into absent when wheezes or crackles were marked as "absent" or "possible" by both observers. Findings classified as "present" by one observer and "absent" by the other were discussed in a face-to-face meeting with all the four observers. Agreement between at least three out of four observers was required to classify an ALS as "present". At the same session, difficult sounds from step two and sounds categorized as "other sounds" were classified.
All observers performed an audiometry at the time of involvement in the project. All observers had normal hearing.

\section{Statistical methods}

We calculated age-standardized prevalence of wheezes and crackles in men and women using the population distribution from the municipality of Troms $\varnothing$ per January 2018 [28]. The ALS were divided into three categories: wheezes and no crackles, crackles and no wheezes, and both wheezes and crackles, irrespective of respiratory phase. We calculated prevalence by participant characteristics and used linear models to explore statistically significant differences among the groups. Tukey's procedure was used to account for multiple testing. The continuous variables were dichotomized with cutoff values for age $\geq 65$ years, for oxygen saturation $\leq 95 \%$ [29], mMRC score $\geq 2$ [30], Body Mass Index (BMI) $\geq 30$ (obesity threshold) and $\mathrm{FEV}_{1}$ below the lower limit of normal (LLN), according to the Global Lung Initiative reference [26].

We used univariable logistic regression to study wheezes and crackles in relation to the variables of interest. In this analysis, wheezes were counted as present also when accompanied by crackles and vice versa. The following outcome variables were considered separately: (1) any wheeze, (2) wheezes only during the inspiratory phase, (3) wheezes during the expiratory phase and (4) wheezes during the expiratory phase at two or more recording sites. For crackles, the outcomes were (1) any crackle, (2) inspiratory crackles, (3) inspiratory crackles at two or more locations, (4) only expiratory crackles. The categorical variables of $\mathrm{FEV}_{1}<\mathrm{LLN}$ and $\mathrm{SpO}_{2} \leq 95 \%$ were substituted by continuous data $\left(\mathrm{FEV}_{1} \mathrm{Z}\right.$-score and $\mathrm{SpO}_{2} \%$ ) to avoid loss of information. We divided age per decades and kept it as a continuous variable. The variables of self-reported disease were dichotomized as 
present (which included both present or past diagnosis) and absent (never diagnosed).

All statistically significant variables for each outcome in the univariable analyses were entered into multivariable logistic regression models. We performed a backward elimination procedure with a threshold of $p<.05$ to obtain the best fitting models for each outcome. We plotted Receiver Operator Characteristics (ROC) curves for all the final models and calculated the area under the curve (AUC) with the r package "pROC" [31]. Multicollinearity in the final models was assessed using variance inflation factor with the statistical package "car" [32]. We used R statistical computing version 3.2.1 package to perform all the calculations [33]. Results were considered significant at $5 \%$ level.

\section{Results}

\section{Participants}

Troms $\varnothing 7$ had an attendance of 21,083 (65\%) in the first visit [22]. Of these, 9253 had been selected in advance to be invited to the second visit, and 90\% $(n=8346)$ took part. Limited by absences of the staff, we recorded lung sounds in 6035 (72.3\%). Restricted by human resources and time constraints, only 4033 participants were included in the classification procedure. Our final number of participants represents $19.1 \%$ of the participation in Tromsø 7 and $48.3 \%$ of those attending the second visit. A comparison of the main characteristics between all the participants of Tromsø 7 and the final study sample and the flow diagram of the participants included in our analyses are available online. (Additional file 1: Table S1, Additional file 2: Figure S1).

\section{General characteristics of the groups}

The mean age of all 4033 participants was 63.5 years, and $2159(53.5 \%)$ were female. (Table 1). There were $477(11.0 \%)$ and $2372(47 \%)$ current and previous smokers, respectively. We found an $\mathrm{FEV}_{1}<\mathrm{LLN}$ in 286 (7.1\%) participants and $182(4.5 \%)$ had oxygen saturation $\leq 95 \%$ (Table 1). We observed that women had lower proportion of myocardial infarction, heart failure and past smokers, but they presented a higher proportion of self-reported asthma, dyspnea (mMRC) and oxygen saturation $\leq 95 \%$.

\section{Classification agreement}

We included 24,198 (4033 $\times 6$ recording sites) recordings for classification. At the first step the observers agreed on inspiratory wheezes in $98.7 \%$ of the recordings (kappa $(\mathrm{k})=0.43 ; 95 \% \mathrm{CI} \quad 0.37-0.49)$, on expiratory wheezes $96.2 \%(\mathrm{k}=0.56 ; 0.53-0.59)$, on inspiratory crackles in $96.5 \%(\mathrm{k}=0.46 ; 0.42-0.49)$, and on expiratory crackles in $98.5 \%(\mathrm{k}=0.20 ; 0.15-0.25)$. Examples of the recordings can be consulted online (Additional file 3: Figure S3).
At the second step, 1257 recordings were marked as containing wheezes and 894 containing crackles. At the third step we discarded wheezes in 224 of these recordings and crackles in 174.

The presented prevalence of ALS are based on six recordings in 3771 (93.5\%) participants. However, in 262 (6.5\%) of the participants included in the analysis there was noise in one or more recordings. Five recording sites were considered in 223 (5.5\%) participants and four or less recording sites in 39 (1\%) participants.

\section{Prevalence of wheezes and crackles}

We found $28 \%(n=1131)$ of individuals with ALS at least at one recording site. Of these, 599 (14.9\%) had only wheezes, $402(10.0 \%)$ had only crackles and 130 (3.2\%) had both wheezes and crackles (Table 2). Expiratory wheezes and inspiratory crackles were the most common findings (Fig. 1). Of the 729 participants with wheezes, $534(73.3 \%)$ had wheezes at one location, 132 (18.1\%) at two locations, $63(8.6 \%)$ at three or more locations. Of the 532 participants with crackles, 381 (71.6\%) had crackles at one recording site, 127 (23.9\%) at two recording sites, $24(4.5 \%)$ at three or more recording sites. Inspiratory crackles were more frequent at the bases (Fig. 1).

The age-standardized prevalence of wheezes was $18.6 \%$ for women and $15.3 \%$ for men and of crackles, 10.8 and $9.4 \%$, respectively. The prevalence of ALS increased significantly with age in both men and women $(p<.001)$. This was particularly the case for crackles (Fig. 2). Pleural rub and bronchial breathing were rarely noticed, each in only two participants.

Wheezes or crackles were found in more than $40 \%$ of participants with the following characteristics: self-reported COPD, $\mathrm{mMRC} \geq 2, \mathrm{FEV}_{1}<\mathrm{LLN}$ and $\mathrm{SpO}_{2} \leq 95 \%$ (Table 2). These characteristics were also associated with the highest prevalence of having both wheezes and crackles, $6.6-8.8 \%$ (Table 2).

\section{Predictors of wheezes}

In the univariable analysis, we found that wheezes were associated with age (10 years increase), female gender, self-reported asthma, current smoking, $\mathrm{mMRC} \geq 2$, and a reduction in $\mathrm{FEV}_{1} \mathrm{Z}$-score, (Table 3). The associations with $\mathrm{mMRC} \geq 2$, current smoking and $\mathrm{FEV}_{1} \mathrm{Z}$-score were stronger for inspiratory than for expiratory wheezes. In the multivariable analysis age, female gender, self-reported asthma, and current smoking predicted the occurrence of expiratory wheezes (Table 4). $\mathrm{FEV}_{1}-\mathrm{Z}$ score was a significant predictor for the occurrence of inspiratory wheezes. The AUC for all the multivariable models were similar (0.59-0.60, Table 4). Multicollinearity was not problematic since the maximum variance inflation factor was $<1.07$. 
Table 1 Characteristics of the study population

\begin{tabular}{|c|c|c|c|}
\hline & $\begin{array}{l}\text { Male } \\
(n=1874) \\
n(\%)\end{array}$ & $\begin{array}{l}\text { Female } \\
(n=2159) \\
\mathrm{n}(\%)\end{array}$ & $\begin{array}{l}\text { Missing } \\
(n=4033) \\
n(\%)\end{array}$ \\
\hline Age & $63.7( \pm 10.5)$ & $63.4( \pm 10.7)$ & \\
\hline$<65$ years & $908(48.5 \%)$ & $1071(49.6 \%)$ & \\
\hline$\geq 65$ years & $966(51.5 \%)$ & $1088(50.4 \%)$ & \\
\hline Body-mass index & & & $12(0.3 \%)$ \\
\hline$<30$ & 1425 (76.0\%) & $1683(78.0 \%)$ & \\
\hline$\geq 30$ & 445 (23.7\%) & $468(21.7 \%)$ & \\
\hline Smoking status & & & $59(1.5 \%)$ \\
\hline Never smoker & $686(36.6 \%)$ & $916(42.4 \%)^{* * *}$ & \\
\hline Current smoker & $208(11.1 \%)$ & $269(12.5 \%)$ & \\
\hline Previous smoker & $954(50.9 \%)$ & $941(43.6 \%)^{* * *}$ & \\
\hline \multicolumn{4}{|l|}{ Self-reported disease } \\
\hline Hypertension & $473(25.2 \%)$ & $557(25.8 \%)$ & $119(3.0 \%)$ \\
\hline Myocardial Infarction & $141(7.5 \%)$ & $57(2.6 \%)^{* * *}$ & $171(4.2 \%)$ \\
\hline Heart failure & $33(1.8 \%)$ & $16(0.7 \%)^{* *}$ & $175(4.3 \%)$ \\
\hline Atrial Fibrillation & $92(4.9 \%)$ & $80(3.7 \%)$ & $178(4.4 \%)$ \\
\hline COPD & $74(3.9 \%)$ & $87(4.0 \%)$ & $157(3.9 \%)$ \\
\hline Asthma & $128(6.8 \%)$ & $196(9.1 \%)^{* *}$ & $254(6.3 \%)$ \\
\hline Rheumatoid arthritis & $83(4.4 \%)$ & $117(5.4 \%)$ & $227(5.6 \%)$ \\
\hline Airways infection last week $\S$ & $278(14.8 \%)$ & $303(14.0 \%)$ & $165(4.1 \%)$ \\
\hline \multicolumn{4}{|l|}{ Dyspnea } \\
\hline $\mathrm{mMRC}$ & & & $165(4.1 \%)$ \\
\hline $\mathrm{mMRC} 0$ & $1323(70.6 \%)$ & $1368(63.4 \%)^{* * *}$ & \\
\hline mMRC 1 & $412(22.0 \%)$ & $575(26.6 \%)^{* * *}$ & \\
\hline mMRC 2-4 & $70(3.7 \%)$ & $120(5.6 \%)^{* *}$ & \\
\hline Breathing worse than usual $\S$ & $210(11.2 \%)$ & $242(11.2 \%)$ & $156(3.9 \%)$ \\
\hline Oxygen saturation, $\mathrm{SpO}_{2}$ & & & $161(4.0 \%)$ \\
\hline$\leq 95 \%$ & $110(5.9 \%)$ & $72(3.3 \%)^{* * *}$ & \\
\hline \multicolumn{4}{|l|}{ Spirometry } \\
\hline $\mathrm{FEV}_{1}<\mathrm{LLN}+$ & $150(8.0 \%)$ & $136(6.3 \%)$ & $234(5.8 \%)$ \\
\hline
\end{tabular}

Abbreviations: $m M R C=$ Modified Medical Research Council questionnaire, $F E V_{1}=$ Forced Expiratory Volume in one second, $L L N=L^{2}$ ower Limit of Normal §On examination day

${ }^{* * *} p$ value $<.001,{ }^{* *} p$ value $<.01,{ }^{*} p$ value $<.05$ as compared to male by $\mathrm{X}^{2}$ test

\section{Predictors of crackles}

The explanatory variables were stronger predictors of crackles than of wheezes (Table 3). Age and gender were the only variables associated with expiratory crackles. For inspiratory crackles, the effect of age, self-reported COPD, asthma, current and previous smoking, $m M R C \geq 2$, oxygen saturation and $\mathrm{FEV}_{1} \mathrm{Z}$-score was stronger when inspiratory crackles were found at two or more recording sites than for inspiratory crackles at one site only. Similarly, in the multivariable analysis the strongest associations were found in the model with inspiratory crackles heard at two or more sites as outcome. This was the model with the highest area under the curve $(\mathrm{AUC}=0.79$ ). Inspiratory crackles appeared more often and at more locations in individuals with a negative $\mathrm{FEV}_{1} \mathrm{Z}$-score and low oxygen saturation (Fig. 3). Multicollinearity was not problematic since the maximum variance inflation factor was $<1.01$.

Predictors of wheezes and crackles in the same subject In the multivariable analysis with both wheezes and crackles as outcome, age, female gender and $\mathrm{FEV}_{1} \mathrm{Z}$ score were the significant predictors (data not shown). The AUC of the model was 0.7.

The variables "respiratory infection previous week" and "more short of breath than usual" predicted neither wheezes nor crackles. 
Table 2 Frequency of wheezes, crackles and both by characteristics of the study population

\begin{tabular}{|c|c|c|c|c|}
\hline & Normal & Wheezes, no crackles & Crackles, no wheezes & $\begin{array}{l}\text { Both crackles and wheezes } \\
n(\%)\end{array}$ \\
\hline & n (\%) & n (\%) & $\mathrm{n}(\%)$ & $\mathrm{n}(\%)$ \\
\hline All $(n=4033)$ & $2902(72.0 \%)$ & $599(14.9 \%)$ & $402(10.0 \%)$ & $130(3.2 \%)$ \\
\hline \multicolumn{5}{|l|}{ Age } \\
\hline$<65$ years & 1539 (77.8\%) & $277(14.0 \%)^{* *}$ & $123(6.2 \%)^{* * *}$ & $40(2.0 \%)^{* * *}$ \\
\hline$\geq 65$ years & $1363(66.4 \%)$ & $322(15.7 \%)$ & $279(13.6 \%)$ & 90 (4.4\%) \\
\hline \multicolumn{5}{|l|}{ Gender } \\
\hline Male & 1389 (74.1\%) & $190(13.4 \%)$ & $251(10.1 \%)$ & $44(2.3 \%)$ \\
\hline Female & $1513(70.1 \%)$ & $348(16.1 \%) *$ & $212(9.8 \%)$ & $86(4.0 \%)^{* *}$ \\
\hline \multicolumn{5}{|l|}{ Body-mass index } \\
\hline$<30$ & $2232(71.8 \%)$ & $483(15.5 \%)^{*}$ & $292(9.4 \%)$ & $101(3.2 \%)$ \\
\hline$\geq 30$ & $663(72.6 \%)$ & $114(12.5 \%)$ & $107(11.7 \%)$ & $29(3.2 \%)$ \\
\hline \multicolumn{5}{|l|}{ Smoking status } \\
\hline Never smoker & $1209(75.5 \%)$ & $227(14.2 \%)$ & $133(8.3 \%)^{* *}$ & $33(2.1 \%)^{* *}$ \\
\hline Current smoker & $299(62.7 \%)$ & $89(18.7 \%) * *$ & $64(13.4 \%) * *$ & $25(5.2 \%)^{* *}$ \\
\hline Previous smoker & 1349 (71.2\%) & $278(14.7 \%)$ & $198(10.4 \%)$ & $70(3.7 \%)$ \\
\hline \multicolumn{5}{|l|}{ Self-reported disease } \\
\hline Healthy $\dagger$ & $1177(76.8 \%)$ & $218(14.0 \%)$ & $120(7.0 \%)^{* * *}$ & $38(2.4 \%)^{*}$ \\
\hline Hypertension & $722(70.1 \%)$ & $151(14.7 \%)$ & $120(11.7 \%)$ & $37(3.6 \%)$ \\
\hline Myocardial Infarction & $123(62.1 \%)$ & $35(17.7 \%)$ & $30(15.2 \%) *$ & $10(5.1 \%)$ \\
\hline Heart failure & $32(65.3 \%)$ & $11(22.4 \%)$ & $5(10.2 \%)$ & $1(2.0 \%)$ \\
\hline Atrial Fibrillation & $114(66.3 \%)$ & 29 (16.9\%) & $25(14.5 \%)$ & $4(2.3 \%)$ \\
\hline COPD & $95(59.0 \%)$ & $27(16.8 \%)$ & $30(18.6 \%)^{* * *}$ & $9(5.6 \%)$ \\
\hline Asthma & $209(64.5 \%)$ & $55(17.0 \%)$ & $38(11.7 \%)$ & $22(6.8 \%)^{* *}$ \\
\hline Rheumatoid arthritis & $129(64.5 \%)$ & $29(14.5 \%)$ & $30(15.0 \%) *$ & $12(6.0 \%)$ \\
\hline Airways infection last week $\S$ & $427(73.5 \%)$ & $89(15.3 \%)$ & $44(7.6 \%)^{*}$ & $21(3.6 \%)$ \\
\hline \multicolumn{5}{|l|}{ Dyspnea } \\
\hline \multicolumn{5}{|l|}{$\mathrm{mMRC}$} \\
\hline $\mathrm{mMRC} 0$ & 1996 (74.2\%) & $388(14.4 \%)$ & $239(8.9 \%)^{* *}$ & $68(3.7 \%)^{* *}$ \\
\hline mMRC 1 & $688(69.7 \%)$ & $148(15.0 \%)$ & $111(11.2 \%)$ & $40(4.1 \%)$ \\
\hline mMRC 2-4 & $109(57.4 \%)$ & $30(15.8 \%)$ & $36(18.9 \%)^{* * *}$ & $15(7.9 \%) * * *$ \\
\hline Breathing worse than usual $\S$ & $321(71.0 \%)$ & $70(15.5 \%)$ & $47(10.4 \%)$ & $14(3.1 \%)$ \\
\hline \multicolumn{5}{|l|}{ Oxygen saturation $\mathrm{SpO}_{2}$} \\
\hline$\leq 95 \%$ & $106(58.2 \%)$ & $25(13.7 \%)$ & $35(19.1 \%)^{* * *}$ & $16(8.8 \%)^{* * *}$ \\
\hline \multicolumn{5}{|l|}{ Spirometry } \\
\hline $\mathrm{FEV}_{1}<\mathrm{LLN} \neq$ & $175(61.2 \%)$ & $52(18.2 \%)$ & $40(14.0 \%)^{*}$ & $19(6.6 \%)^{* * *}$ \\
\hline
\end{tabular}

Abbreviations: $m M R C=$ Modified Medical Research Council questionnaire, $F E V_{1}=$ Forced Expiratory Volume in one second, $L L N=L^{2}$ ower limit of Normal Plus-minus values are means $+-\mathrm{SD}$

Percentages (\%) represent the distribution of each variable between the different groups

${ }^{* * *} p$ value $<.001,{ }^{* *} p$ value $<.01,{ }^{*} p$ value $<.05$ as compared to normal

† Not current smokers who stated not to have any of the diseases considered for this analysis

₹ Calculated from Global Lung Function Initiative reference (GLI)

$\S$ On examination day

\section{Discussion}

Wheezes and crackles were common findings. Any of these sounds were found in almost one third of our sample. Wheezes and crackles were associated with increasing age. The sounds were not always related to clinically diagnosed disease, but their prevalence increased in the presence of decreased lung function or chronic shortness of breath.

We are not aware of any comparable study carried out in a general population. An investigation with 700 


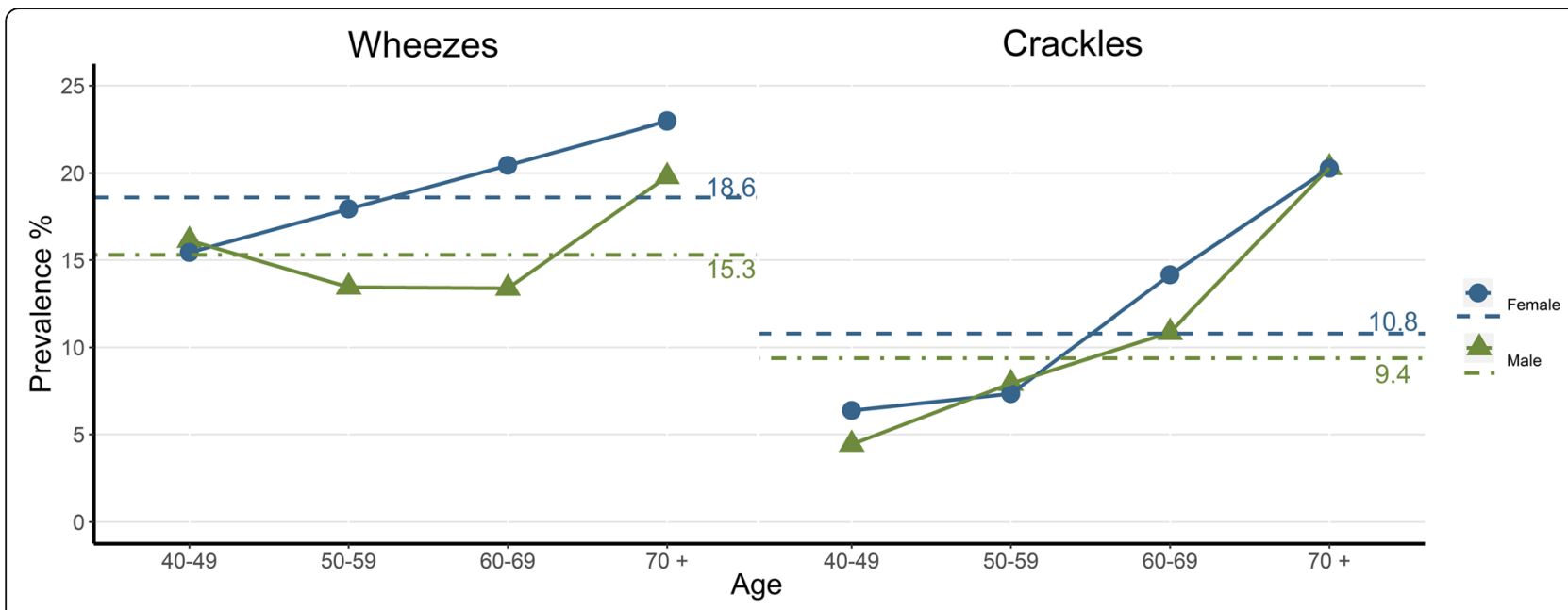

Fig. 2 Prevalence of wheezes and crackles by age (in years). Dotted lines represent standardized prevalence rates

participants conducted by Murphy et al., found wheezes and rhonchi in 4 and $4 \%$, respectively, in a subgroup of 334 apparently healthy adults. Wheezes were heard in $59 \%$ of patients with asthma. For crackles, the prevalence was $21 \%$ in the apparently healthy group and $71 \%$ in patients with COPD. [10] These prevalences were higher than what we observed, except for wheezes in the apparently healthy group. In their study, the age of the participants was not taken into account. They included more recording sites than in ours and used a computerized classification of the sounds. Different sensitivities of the classification methods may partly explain the discordance in prevalence. Crackles detected by a computer algorithm may be inaudible with a stethoscope since crackles may be masked by normal sounds. [34].

In most participants with ALS in our study, these were heard at only one of the six recording sites. The number of sites with positive findings had an impact on the associations. The model with inspiratory crackles at two or more locations as outcome performed better than the model predicting any crackles, reaching an AUC of 0.79. No similar effect of increasing number of sites was found regarding wheezes.

The importance of age was described by Kataoka et al., who observed a rising prevalence of crackles from $11 \%$ in cardiovascular asymptomatic adults 40-65 years to $70 \%$ in participants $80-95$ years old. [35] Murphy et al. found an association with age among asbestos exposed workers. [36] Age relates to a reduction of supporting tissue around the airways causing a premature closure of the airways. [37]. The influence of lung and heart disease associated with ageing might have contributed to the strong association between crackles and age in our study, an influence beyond what indicated by self-reported diseases, spirometry and pulse oximetry.
Self-reported asthma was associated with wheezes, which was in line with previous studies. [3] Hypertension, self-reported asthma, myocardial infarction, self-reported COPD, and RA were associated with crackles in the univariable analysis, but only the latter two remained statistically significant in the multivariable models. The association of crackles with RA could be explained by the presence of parenchymal lung abnormalities in patients with this diagnosis. [38] However, we did not have an independent confirmation of the diagnosis. Self-reported heart failure was not associated with crackles probably due to underdiagnosed heart failure [39]. Interestingly, symptoms suggestive of airway infection the week before the examination was not an independent predictor of crackles or wheezes. In a European study from primary care of 2810 adults with acute cough, crackles were registered in $31 \%$ of patients in the pneumonia group. [40] Since the prevalence of pneumonia in this study was only $5 \%$, and probably far less in our study, it is likely that crackles represented chronic rather than acute changes in the lungs in most cases.

Women had a higher prevalence of wheezes than men. Considering subcategories of wheezes, this observation was valid for expiratory but not for inspiratory wheezes. The same gender disparity has been reported in epidemiological studies on self-reported wheeze [41, 42]. Although wheezing is more common in male newborns and infants, this gender difference seems to change sometime during adolescence when females start to show a higher risk of wheezing. [43] Our findings indicate that this may persist into later adulthood.

Oxygen saturation was significantly associated with the presence of inspiratory crackles. Crackles are related to the sudden opening of closed airways or to air movement through obstructed airways. [44] These conditions may impair ventilation/perfusion matching, the most 


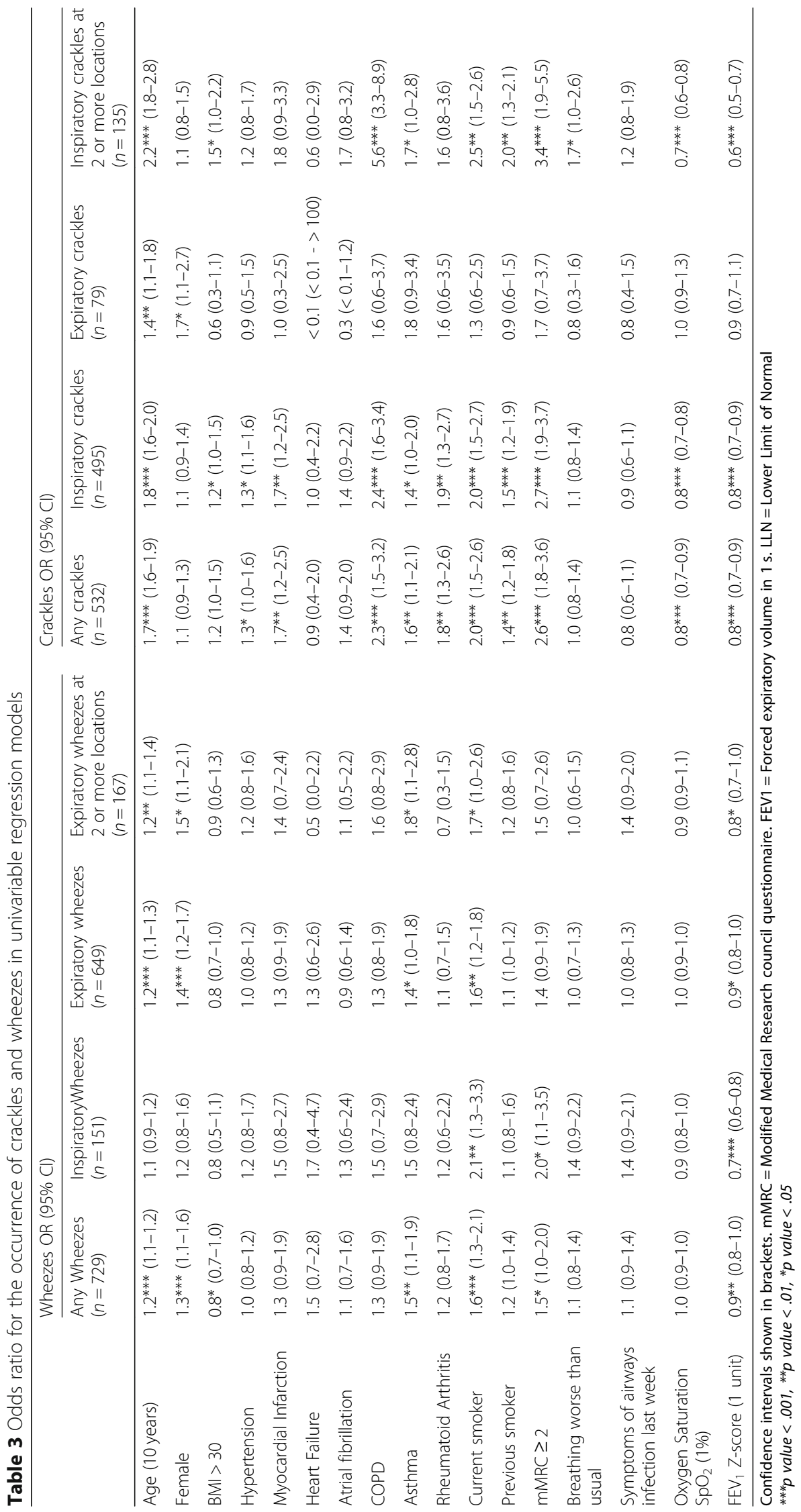


Table 4 Odds ratio for the occurrence of crackles and wheezes in multivariable regression models

\begin{tabular}{|c|c|c|c|c|c|c|}
\hline & $\begin{array}{l}\text { Inspiratory wheezes } \\
(n=130)\end{array}$ & $\begin{array}{l}\text { Expiratory wheezes } \\
(n=587)\end{array}$ & $\begin{array}{l}\text { Expiratory wheezes } 2+ \\
(n=151)\end{array}$ & $\begin{array}{l}\text { Inspiratory crackles } \\
(n=445)\end{array}$ & $\begin{array}{l}\text { Expiratory crackles } \\
(n=70)\end{array}$ & $\begin{array}{l}\text { Inspiratory crackles } 2+ \\
(n=118)\end{array}$ \\
\hline Age $(\times 0.1)$ & - & $1.2^{* * *}(1.1-1.3)$ & $1.2^{* *}(1.1-1.5)$ & $1.8^{* * *}(1.6-2.0)$ & $1.5^{* *}(1.2-1.9)$ & $2.2^{* * *}(1.8-2.9)$ \\
\hline Female Gender & - & $1.5^{* * *}(1.2-1.8)$ & $1.5^{*}(1.1-2.1)$ & - & - & - \\
\hline COPD & - & - & - & - & - & $2.3^{* *}(1.3-4.1)$ \\
\hline Asthma & - & $1.4^{*}(1.0-1.8)$ & $1.9^{* *}(1.1-3.0)$ & - & - & - \\
\hline $\begin{array}{l}\text { Rheumatoid } \\
\text { Arthritis }\end{array}$ & - & - & - & $1.6^{*}(1.1-2.3)$ & - & - \\
\hline Current smoker & - & $1.7^{* * *}(1.3-2.2)$ & - & $1.9^{* * *}(1.4-2.7)$ & - & - \\
\hline Previous smoker & - & $1.1(0.9-1.3)$ & - & $1.3^{*}(1.0-1.6)$ & - & - \\
\hline $\mathrm{mMRC} \geq 2$ & - & - & - & $1.8^{* *}(1.2-2.6)$ & - & - \\
\hline $\begin{array}{l}\text { Oxygen saturation } \\
\mathrm{SpO}_{2}(1 \%)\end{array}$ & - & - & - & $0.9^{* *}(0.8-1.0)$ & - & $0.7^{* * *}(0.6-0.8)$ \\
\hline $\begin{array}{l}\mathrm{FEV}_{1} \text { Z-score (1 } \\
\text { unit) }\end{array}$ & $0.7^{* * *}(0.6-0.8)$ & - & - & $0.9^{* *}(0.8-1.0)$ & - & $0.7^{* * *}(0.6-0.8)$ \\
\hline AUC & $.59(0.54-0.64)$ & $.59(0.56-0.62)$ & $.60(0.55-0.64)$ & $.69(0.67-0.72)$ & $.62(0.56-0.69)$ & $.79(0.75-0.84)$ \\
\hline
\end{tabular}

Confidence intervals shown in brackets. $2+=$ presence of the adventitious sounds in more than two locations. $m M R C=$ Modified Medical Research council questionnaire. $F E V 1=$ Forced expiratory volume in $1 \mathrm{~s}, A \cup C=$ Area under the curve

${ }^{* * *} p$ value $<.001,{ }^{* *} p$ value $<.01,{ }^{*} p$ value $<.05$

common cause of hypoxemia, which could explain the relationship in our study. [37].

\section{Strengths and limitations}

To our knowledge, this is the largest sample characterizing the occurrence of wheezes and crackles to date. Tromsø 7 had a high response rate (65\%). The study has a high external validity for the Norwegian population. [23] Nevertheless, our results might not be valid in other populations, for instance in those with poorer health. Unhealthy people may be underrepresented since some might have chosen to refrain from participation or were not able to attend and complete the survey.

The questionnaires employed at Tromsø 7 did not ask about the presence of interstitial lung disease and bronchiectasis. Both conditions have an increased prevalence with age $[45,46]$ and are associated with the presence of crackles $[6,7]$. It is possible that participants with these conditions were categorized as apparently healthy and this constitutes a limitation of our study.

All the selection processes were randomized and took place prior to the classification of the recordings without

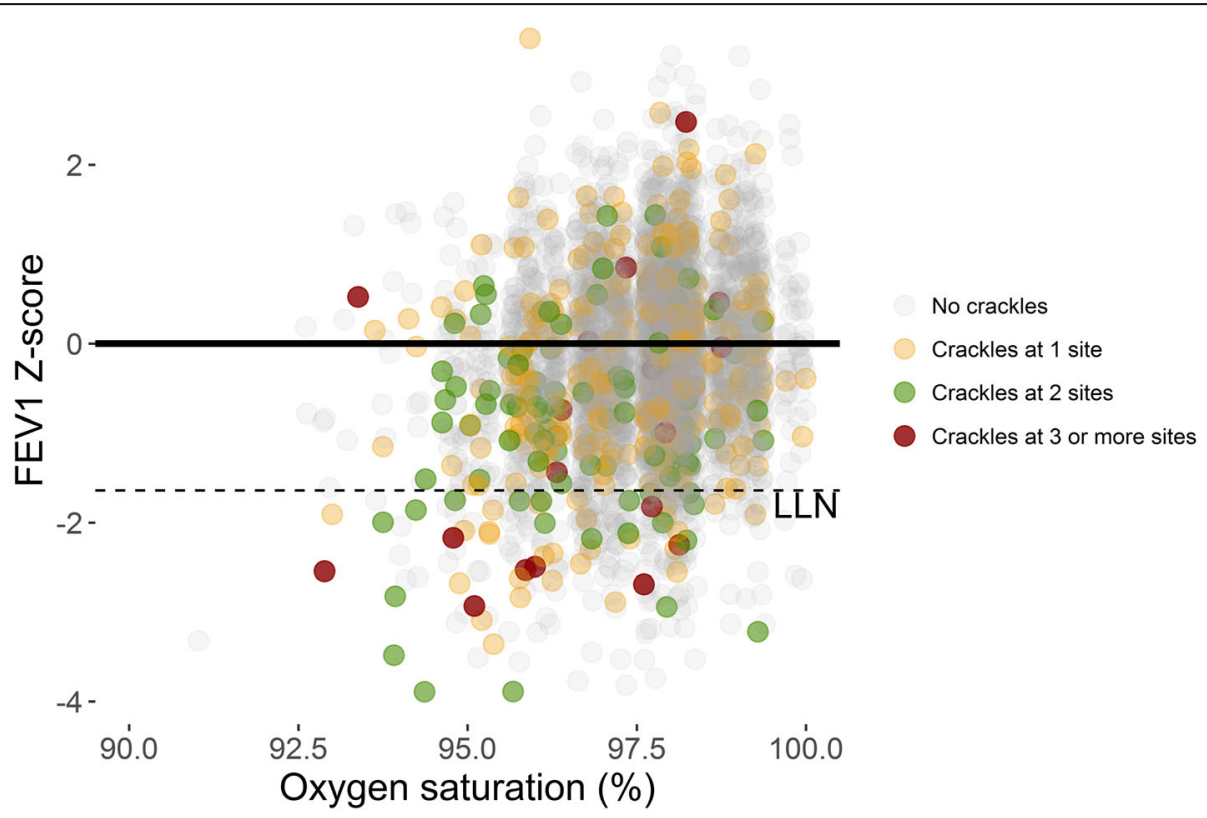

Fig. 3 Occurrence of Inspiratory crackles by Z-score FEV1 (reference GLI 2012) and SpO2. LLN = Lower Limit of Normal 
having any knowledge of the health status of the participants. When randomizing for the second visit a higher representation was chosen among those aged 60 years or more, and the subjects invited due to participation in previous surveys of the Tromsø study were usually 60 years or older. In terms of prevalence, we have taken care of this selection bias by age standardization, but some influence on associations with self-reported diseases and lung function cannot be excluded.

The inter-observer agreement at the first step of our classification compares to that found among general practitioners. [47] The repeated independent classifications have without doubt increased the reliability. [48] A lack of reliability could have influenced our results by diluting the strength of the estimates. At the third step of the classification, we chose to discard as positive findings the recordings marked as "possible" by two observers. In a sensitivity analysis, they were classified as "present" but the results were similar, and our conclusions unchanged.

\section{Conclusion}

Our findings support a cautious attitude when using ALS to diagnose lung disease in elderly patients. The presence of wheezes or crackles in one lung location did not strongly predicted the outcomes analyzed. Nonetheless, it is possible that these solitary findings are a manifestation of lung senescence and/or represent subclinical disease in apparently healthy subjects. However, when inspiratory crackles at two or more locations or both wheezes and crackles are heard, risk of decreased lung function increases considerably. Such findings, particularly when unexpected in a patient, should lead to further investigation regarding possible heart or lung disease.

\section{Additional files}

\section{Additional file 1: Table S1. Comparison between all the participants} attending the 7th Survey of the Troms $\varnothing$ Study and the final sample included in this article. (DOCX $12 \mathrm{~kb}$ )

Additional file 2: Figure S1. Flow diagram of the participants included in our analyses. (JPG $292 \mathrm{~kb}$ )

Additional file 3: Figure S2. Spirogram and clinical information of four participants with presence of adventitious lung sounds in the recordings. (PPTX $2605 \mathrm{~kb}$ )

\section{Abbreviations}

ALS: Adventitious Lung Sounds; AUC: Area Under the Curve; COPD: Chronic Obstructive Pulmonary Disease; FEV ${ }_{1}$ : Forced Expiratory Volume in $1 \mathrm{~s}$; GLI: Global Lung Initiative; LLN: Lower Limit of Normal; mMRC: Modified Medical Research Council dyspnea scale; OR: Odds Ratio; RA: Rheumatoid Arthritis; $\mathrm{SpO}_{2}$ : Arterial oxygen saturation

\section{Acknowledgements}

We would like to thank Katrine Wang, Gøril Henriksen and Lars Tunby for their help with data collection. We would also like to thank all participants in the Tromsø 7th study, as well as the staff, to make this research possible. The publication charges for this article have been funded by a grant from the publication fund of UiT The Arctic University of Norway.
Ethical approval and consent to participate

All study participants provided written consent. The Regional Committee for Medical and Health Research Ethics in North Norway approved the study.

\section{Author contributions}

$\mathrm{MH}$ conceived the research idea. ASJC, DA and ER had responsibility for data collection. ASJC, JC, DA, ER, PH and MH participated in the classification of lung sounds. ASJC, MH and SV had responsibility for the data analysis. ASJC and $\mathrm{MH}$ had the responsibility for the main drafting of the manuscript. All authors contributed substantially to the interpretation of the results, and completion of the manuscript. All authors approved the final manuscript.

\section{Funding}

UiT, The Arctic University of Norway. The funding source had no role in study design, data collection and analysis, decision to publish, or preparation of the manuscript.

\section{Availability of data and materials}

The data that support the findings of this study are available from The Troms $\varnothing$ Study but restrictions apply to the availability of these data, which were used under license for the current study, and so are not publicly available. Information and guidelines to apply for access to data from The Troms $\varnothing$ study are available at https://en.uit.no/prosjekter/prosjekt?p document_id=71247.

\section{Consent for publication}

Written informed consent was obtained from the patient for publication of Fig. 1. A copy of the written consent is available for review by the Editor of this journal.

\section{Competing interests}

The authors declare that they have no competing interests.

\section{Author details}

${ }^{1}$ General Practice Research Unit, Department of Community Medicine, UIT the Arctic University of Norway, Tromsø, Norway. ${ }^{2}$ CINTESIS - Center for Health Technology and Services Research, Faculty of Medicine, University of Porto, Porto, Portugal. ${ }^{3}$ Department of methodology and statistics, University of Maastricht, Maastricht, The Netherlands. ${ }^{4}$ Department of Pediatrics and Child Health, University of Manitoba, Winnipeg, Canada.

Received: 27 February 2019 Accepted: 26 August 2019

Published online: 11 September 2019

\section{References}

1. van der Wall EE. The stethoscope: celebration or cremation after 200 years? Neth Heart J. 2016;24(5):303-5

2. Edelman ER, Weber BN. Tenuous tether. N Engl J Med. 2015:373(23): 2199-201.

3. Pasterkamp $\mathrm{H}$. The highs and lows of wheezing: a review of the most popular adventitious lung sound. Pediatr Pulmonol. 2018;53(2):243-54

4. Jacome C, Marques A. Computerized respiratory sounds in patients with COPD: a systematic review. COPD. 2015;12(1):104-12

5. Bennett S, Bruton A, Barney A, Havelock T, Bennett M. The relationship between crackle characteristics and airway morphology in COPD. Respir Care. 2015;60(3):412-21.

6. Bohadana A, Izbicki G, Kraman SS. Fundamentals of lung auscultation. N Engl J Med. 2014;370(21):2053.

7. Barker AF. Bronchiectasis. N Engl J Med. 2002:346(18):1383-93.

8. Vyshedskiy A, Bezares F, Paciej R, Ebril M, Shane J, Murphy R. Transmission of crackles in patients with interstitial pulmonary fibrosis, congestive heart failure, and pneumonia. Chest. 2005;128(3):1468-74.

9. Moore M, Stuart B, Little P, Smith S, Thompson MJ, Knox K, et al. Predictors of pneumonia in lower respiratory tract infections: $3 \mathrm{C}$ prospective cough complication cohort study. Eur Respir J. 2017;50(5).

10. Murphy RL. In defense of the stethoscope. Respir Care. 2008:53(3):355-69.

11. Norisue $Y$, Tokuda $Y$, Koizumi M, Kishaba T, Miyagi S. Phasic characteristics of inspiratory crackles of bacterial and atypical pneumonia. Postgrad Med J. 2008;84(994):432-6.

12. Jakobsen KA, Melbye H, Kelly MJ, Ceynowa C, Molstad S, Hood K, et al. Influence of CRP testing and clinical findings on antibiotic prescribing in 
adults presenting with acute cough in primary care. Scand J Prim Health Care. 2010;28(4):229-36.

13. Strumilo J, Chlabicz S, Pytel-Krolczuk B, Marcinowicz L, Rogowska-Szadkowska D, Milewska AJ. Combined assessment of clinical and patient factors on doctors' decisions to prescribe antibiotics. BMC Fam Pract. 2016;17:63.

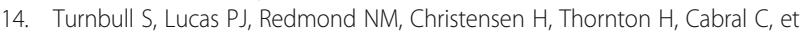
al. What gives rise to clinician gut feeling, its influence on management decisions and its prognostic value for children with RTI in primary care: a prospective cohort study. BMC Fam Pract. 2018;19(1):25.

15. Badgett RG, Lucey CR, Mulrow CD. Can the clinical examination diagnose left-sided heart failure in adults? JAMA. 1997;277(21):1712-9.

16. Holleman DR Jr, Simel DL. Does the clinical examination predict airflow limitation? JAMA. 1995;273(4):313-9.

17. Metlay JP, Kapoor WN, Fine MJ. Does this patient have community-acquired pneumonia? Diagnosing pneumonia by history and physical examination. JAMA. 1997;278(17):1440-5.

18. Thacker RE, Kraman SS. The prevalence of auscultatory crackles in subjects without lung disease. Chest. 1982;81(6):672-4.

19. Oliveira A, Marques A. Respiratory sounds in healthy people: a systematic review. Respir Med. 2014;108(4):550-70.

20. Workum P, Holford SK, Delbono EA, Murphy RL. The prevalence and character of crackles (rales) in young women without significant lung disease. Am Rev Respir Dis. 1982;126(5):921-3.

21. Kostas NP, Leontios JH, Mark LE. Breath sounds from basic science to clinical Pratice. Cham, Switzerland: Springer; 2018

22. UiT The Arctic University of Norway [Internet]. The Tromsø Study. 2019. [Cited 03 Aug 2019] Available from: http://tromsoundersokelsen.uit.no/ tromso/.

23. Jacobsen BK, Eggen AE, Mathiesen EB, Wilsgaard T, Njolstad I. Cohort profile: the Tromso study. Int J Epidemiol. 2012:41(4):961-7.

24. Mahler DA, Wells CK. Evaluation of clinical methods for rating dyspnea. Chest. 1988:93(3):580-6.

25. Miller MR, Hankinson J, Brusasco V, Burgos F, Casaburi R, Coates A, et al. Standardisation of spirometry. Eur Respir J. 2005;26(2):319-38.

26. Quanjer PH, Stanojevic S, Cole TJ, Baur X, Hall GL, Culver BH, et al. Multiethnic reference values for spirometry for the 3-95-yr age range: the global lung function 2012 equations. Eur Respir J. 2012;40(6):1324-43.

27. Vanbelle $\mathrm{S}$. Asymptotic variability of (multilevel) multirater kappa coefficients. Stat Methods Med Res. 2018;EEpub ahead of print. https://doi. org/10.1177/962280218794733.

28. Statistics Norway [Internet]. Tromsø municipality facts (Age distribution pe 1. januar 2018). 2018. [Cited 12 Jan 2018]. Available from: https://www.ssb. no/kommunefakta/tromso.

29. Dalbak LG, Straand J, Melbye H. Should pulse oximetry be included in GPS assessment of patients with obstructive lung disease? Scand J Prim Health Care. 2015;33(4):305-10.

30. Global Initiative for Prevention Diagnosis and Management of COPD (2018). Global strategy for the diagnosis, management, and prevention of chronic obstructive pulmonary disease. 2018 [Online] Available from: https:// goldcopd.org/gold-reports/ . [Accessed 03 Aug. 2019].

31. Xavier Robin NT, Hainard A, Tiberti N, Lisacek F, Sanchez J-C, Müller M. PROC: an open-source package for R and S+ to analyze and compare ROC curves. BMC Bioinformatics. 2011:12:77.

32. Fox J, Weisberg $S$. An $\{R\}$ companion to applied regression. 2nd ed. Thousand Oaks, California, USA: SAGE Publications; 2011.

33. R Core Team. R: a language and environment for statistical computing. Vienna, Austria: R Foundation for Statistical Computing; 2016.

34. Kiyokawa H, Greenberg M, Shirota K, Pasterkamp H. Auditory detection of simulated crackles in breath sounds. Chest. 2001;119(6):1886-92.

35. Kataoka H, Matsuno O. Age-related pulmonary crackles (rales) in asymptomatic cardiovascular patients. Ann Fam Med. 2008;6(3):239-45.

36. Murphy RL Jr, Gaensler EA, Holford SK, Del Bono EA, Epler G. Crackles in the early detection of asbestosis. Am Rev Respir Dis. 1984;129(3):375-9.

37. Janssens JP, Pache JC, Nicod LP. Physiological changes in respiratory function associated with ageing. Eur Respir J. 1999;13(1):197-205.

38. Wilsher M, Voight L, Milne D, Teh M, Good N, Kolbe J, et al. Prevalence of airway and parenchymal abnormalities in newly diagnosed rheumatoid arthritis. Respir Med. 2012;106(10):1441-6.

39. van Riet EE, Hoes AW, Limburg A, Landman MA, van der Hoeven $H$, Rutten FH. Prevalence of unrecognized heart failure in older persons with shortness of breath on exertion. Eur J Heart Fail 2014;16(7):772-7.
40. van Vugt SF, Verheij TJ, de Jong PA, Butler CC, Hood K, Coenen S, et al. Diagnosing pneumonia in patients with acute cough: clinical judgment compared to chest radiography. Eur Respir J. 2013;42(4):1076-82.

41. Arathimos R, Granell R, Henderson J, Relton CL, Tilling K. Sex discordance in asthma and wheeze prevalence in two longitudinal cohorts. PLoS One. 2017;12(4):e0176293.

42. Mandhane PJ, Greene JM, Cowan JO, Taylor DR, Sears MR. Sex differences in factors associated with childhood- and adolescent-onset wheeze. Am J Respir Crit Care Med. 2005;172(1):45-54.

43. Fu L, Freishtat RJ, Gordish-Dressman H, Teach SJ, Resca L, Hoffman EP, et al. Natural progression of childhood asthma symptoms and strong influence of sex and puberty. Ann Am Thorac Soc. 2014;11(6):939-44.

44. Vyshedskiy A, Alhashem RM, Paciej R, Ebril M, Rudman I, Fredberg JJ, et al. Mechanism of inspiratory and expiratory crackles. Chest. 2009;135(1):156-64.

45. Olson AL, Gifford AH, Inase N, Fernandez Perez ER, Suda T. The epidemiology of idiopathic pulmonary fibrosis and interstitial lung diseases at risk of a progressive-fibrosing phenotype. Eur Respir Rev. 2018;27(150).

46. O'Donnell AE. Bronchiectasis Chest. 2008;134(4):815-23.

47. Aviles-Solis JC, Vanbelle S, Halvorsen PA, Francis N, Cals JWL, Andreeva EA, et al. International perception of lung sounds: a comparison of classification across some European borders. BMJ Open Respir Res. 2017;4(1):e000250

48. Kraemer HC, Bloch DA. Kappa coefficients in epidemiology: an appraisal of a reappraisal. J Clin Epidemiol. 1988;41(10):959-68

\section{Publisher's Note}

Springer Nature remains neutral with regard to jurisdictional claims in published maps and institutional affiliations.
Ready to submit your research? Choose BMC and benefit from:

- fast, convenient online submission

- thorough peer review by experienced researchers in your field

- rapid publication on acceptance

- support for research data, including large and complex data types

- gold Open Access which fosters wider collaboration and increased citations

- maximum visibility for your research: over $100 \mathrm{M}$ website views per year

At $\mathrm{BMC}$, research is always in progress.

Learn more biomedcentral.com/submissions 